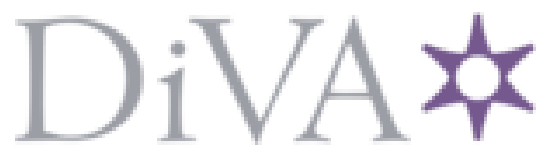

http://www.diva-portal.org

This is the published version of a paper published in Journal of the American Chemical Society.

Citation for the original published paper (version of record):

Martinez-Erro, S., Sanz-Marco, A., Gómez, A B., Vazquez-Romero, A., Ahlquist, M S. et al. (2016)

Base-Catalyzed Stereospecific Isomerization of Electron-Deficient Allylic Alcohols and Ethers through Ion-Pairing.

Journal of the American Chemical Society, 138(40): 13408-13414

https://doi.org/10.1021/jacs.6b08350

Access to the published version may require subscription.

N.B. When citing this work, cite the original published paper.

Reprinted with permission of Journal of the American Chemical Society, 138(40) 13408-13414, Copyrignt 2016 American Chemical Society

Permanent link to this version:

http://urn.kb.se/resolve?urn=urn:nbn:se:su:diva-136066 


\title{
Base-Catalyzed Stereospecific Isomerization of Electron-Deficient Allylic Alcohols and Ethers through lon-Pairing
}

\author{
Samuel Martinez-Erro, ${ }^{\dagger, \S}$ Amparo Sanz-Marco, ${ }^{\dagger}{ }^{\S}$ Antonio Bermejo Gómez, ${ }^{\dagger}$ Ana Vázquez-Romero, ${ }^{\dagger}$ \\ Mårten S. G. Ahlquist, ${ }^{\dagger}$ and Belén Martín-Matute ${ }^{* \dagger}$ \\ ${ }^{\dagger}$ Department of Organic Chemistry, Stockholm University, Stockholm SE-10691, Sweden \\ ${ }^{\ddagger}$ Division of Theoretical Chemistry \& Biology, School of Biotechnology, KTH Royal Institute of Technology, Stockholm SE-10691,
} Sweden

\section{Supporting Information}

ABSTRACT: A mild base-catalyzed strategy for the isomerization of allylic alcohols and allylic ethers has been developed. Experimental and computational investigations indicate that transition metal catalysts are not required when basic additives are present. As in the case of using transition metals under basic conditions, the isomerization catalyzed solely by base also follows a stereospecific pathway. The reaction is initiated by a rate-limiting deprotonation. Formation of an intimate ion pair between an allylic anion and the conjugate acid of the base results in efficient transfer of chirality. Through this mechanism, stereochemical information contained in the allylic alcohols is transferred to the ketone products. The stereospecific isomerization is also applicable for the first time to allylic ethers, yielding synthetically valuable enantioenriched (up to $97 \%$ ee) enol ethers.

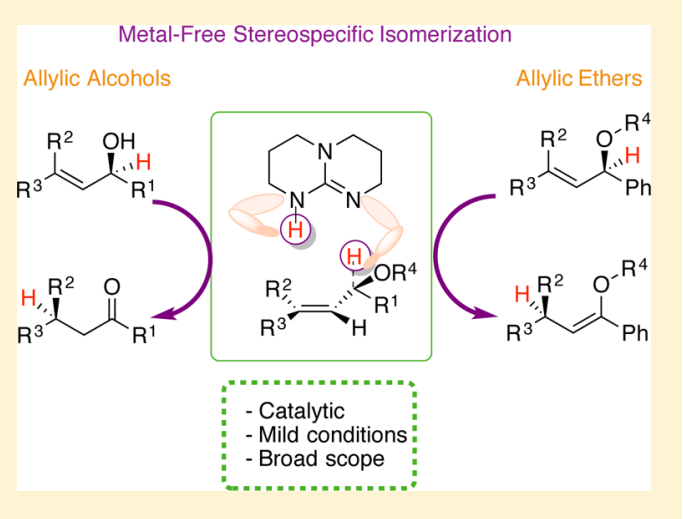

\section{INTRODUCTION}

Allylic alcohols are readily accessible building blocks, and they are versatile synthons of carbonyl compounds via isomerization reactions. In the vast majority of instances, these are mediated by transition metal complexes. ${ }^{1,2}$ Basic additives, in catalytic or stoichiometric amounts, are also needed in numerous transition metal-mediated isomerizations. The base is postulated to deprotonate the substrate alcohol, which can subsequently coordinate to the metal center forming transition metal alkoxides, key intermediates in the proposed catalytic cycles. ${ }^{2 \mathrm{~b}, \mathrm{c}, \mathrm{h}, \mathrm{i}, 3}$ With chiral metal catalysts, the synthesis of chiral ketones ${ }^{2 a, g}$ and aldehydes $^{2 \mathrm{f}-\mathrm{i}}$ with stereogenic centers at $\mathrm{C} \beta$ has been accomplished. An important related approach was reported recently by Cahard, Renaud, and co-workers, ${ }^{4}$ who isomerized chiral $\gamma$-trifluoromethylated allylic alcohols stereospecifically using a nonchiral $\mathrm{Ru}$ complex together with $\mathrm{Cs}_{2} \mathrm{CO}_{3}$. Transition-metal-free base-mediated protocols are much less common in the literature. ${ }^{5}$ These are highly dependent on the substrate structure (e.g., $\mathrm{R}^{1}=\mathrm{R}^{3}=\mathrm{Ar}$ ) and require stoichiometric amounts or excess of the base. Transition-metal-free chiral versions have not been reported.

We have previously reported the synthesis of $\alpha$-halocarbonyls from allylic alcohols catalyzed by Ir complexes. ${ }^{1 c, 6}$ As an ongoing part of our investigations, we have now attempted to apply this methodology to electron-poor allylic alcohols, in particular $\gamma$-trifluoromethylated substrates. We have observed that these substrates isomerize efficiently under basic conditions, even at mild temperature, in the absence of the metal catalysts. Furthermore, the base-catalyzed isomerization achieves the same high levels of stereospecificity with chiral allylic alcohols as those reported for the metal/base system. ${ }^{4}$ Herein, we report the first base-catalyzed stereospecific isomerization of allylic alcohols and also of allylic ethers (Scheme 1). The isomerizations

Scheme 1. Stereospecific Base-Catalyzed Isomerization of Allylic Alcohols and Ethers

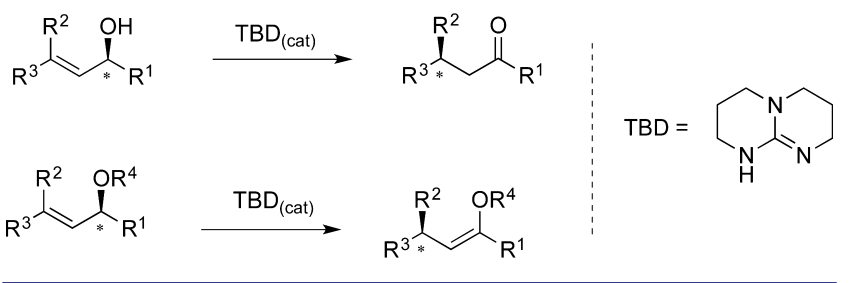

are mediated by a catalytic amount of the base 1,5,7-triazabicyclo[4.4.0]dec-5-ene (TBD). Mechanistic experimental and theoretical investigations have been carried out allowing us to propose a mechanistic isomerization pathway accounting for the efficient transfer of chirality.

\section{RESULTS AND DISCUSSION}

We started by investigating how the base affected the outcome of the isomerization of $\gamma$-trifluoromethylated allylic alcohol 1a (Table 1). $\mathrm{Cs}_{2} \mathrm{CO}_{3}$, which was also used in the isomerization of 1a in combination with $\left[\mathrm{RuCl}_{2}\left(\mathrm{PPh}_{3}\right)_{3}\right],{ }^{4}$ can itself promote the isomerization at $60{ }^{\circ} \mathrm{C}$ (Table 1 , entry 1$)$. Ketone $2 \mathrm{a}$ was

Received: August 10, 2016

Published: September 16, 2016 
Table 1. Base-Mediated Isomerization of 1a
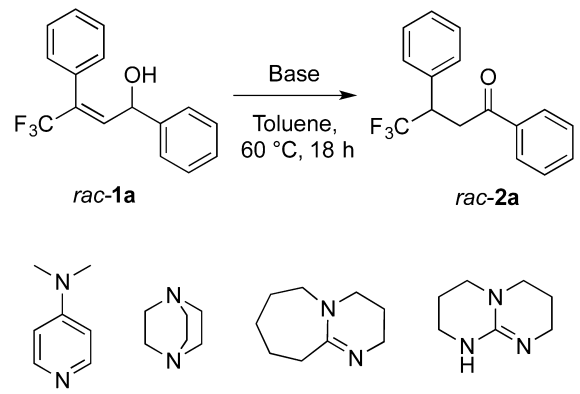

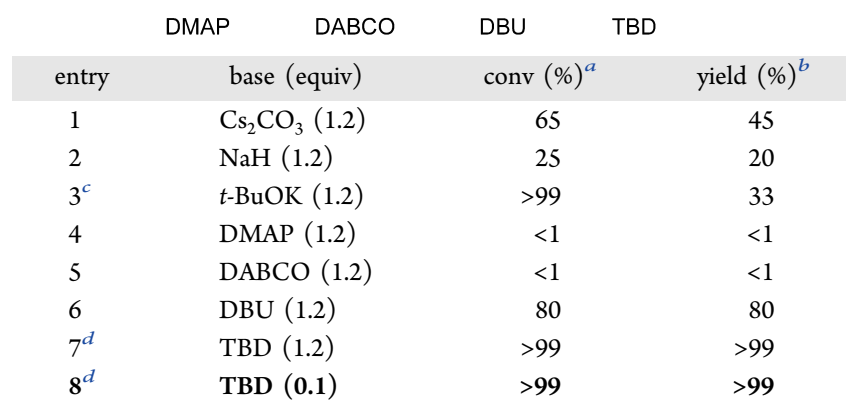

${ }^{a}$ By ${ }^{19} \mathrm{~F}$ NMR spectroscopy. ${ }^{b}$ With an internal standard (IS). ${ }^{c}$ Decomposition products were formed. ${ }^{d}$ Under an atmosphere of air.

also obtained when $\mathrm{NaH}$ and $t$-BuOK were used, albeit in low yield (entries 2 and 3). The use of organic bases such as 4-(dimethylamino)pyridine (DMAP) and 1,4-diazabicyclo[2.2.2]octane $(\mathrm{DABCO})^{5 \mathrm{e}}$ did not promote the isomerization (entries 4 and 5). On the other hand, with the stronger ${ }^{7}$ 1,8-diazabicyclo[5.4.0] undec-7-ene (DBU) or with guanidine base TBD high conversions were achieved (entries 6 and 7), especially with TBD. Importantly, TBD was the only base that could be used in a catalytic amount to give a quantitative yield of 2a (entry 8 and Table S1). The isomerization works under an atmosphere of air, and after full conversion is achieved, a simple aqueous workup to remove the basic catalyst gives the final products in excellent yields.

The scope of the reaction (Scheme 2) under the optimized conditions (Table 1, entry 8) was then investigated. Variation of the electronic properties of the aryl group at $\mathrm{R}^{1}$ by introducing either electron-withdrawing or electron-donating groups gave quantitative yields ( $84-95 \%$ isolated) for all substrates. Notably, the reactions were much faster with electron-poor substituents (Scheme 2, 2b,c). The bulkier naphthyl group was also well tolerated, giving $\mathbf{2 f}$ in $>99 \%$ yield. Excellent yields were also obtained when the aryl substituent at $\mathrm{R}^{1}$ was replaced by the electron-poor $\mathrm{CF}_{3}$ group (2g), although slightly harsher conditions were required. Significantly lower yields were achieved when $\mathrm{R}^{1}$ was replaced by $\mathrm{CH}_{3}$ or $\mathrm{H}$ (Scheme 2, $\mathbf{2 h}, \mathbf{i})$. The effect of varying the olefin substituents was next studied. Allylic alcohols bearing electron-withdrawing or electron-donating groups on aryl subtituents at $\mathrm{R}^{2}$ gave the corresponding products in high yields in all cases (Scheme 2, $2 \mathbf{j}-\mathbf{m})$. Replacement of the aromatic group at $\mathrm{R}^{2}$ by $\mathrm{H}$ or $\mathrm{CH}_{3}$ was well tolerated, and alcohols 10 and $\mathbf{1 n}$ were isomerized in 95-99\% yields. Alcohols $\mathbf{1 p}$ and 1q, with longer fluorinated chains at $\mathrm{R}^{3}$, were also isomerized in good isolated yields $(62 \%$ and $71 \%$, respectively). The isomerization of (E)-1a was compared to that of its stereoisomer $(Z)$-1a. The latter smoothly transformed into $\mathbf{2 a}$, but a higher temperature and a longer reaction time were needed.
Interestingly, the fluorinated motif on the olefin can be replaced by other nonfluorinated groups; $(E)-\mathbf{1 r}\left(\mathrm{R}^{2}=\mathrm{H}\right.$, $\left.\mathrm{R}^{3}=\mathrm{Ph}\right)$ isomerized in excellent yield. Even aromatic $\mathbf{1 s}-\mathbf{u}$ with terminal double bonds isomerized successfully. Allylic alcohols (E)- and (Z)-1v, with nonfluorinated substituents on the double bond, one of them a methyl group, gave lower yields than those obtained with the related 1a. In contrast, with alcohols having two aryl substituents on the double bond $(\mathbf{1 w},(E)-\mathbf{1 x},(Z)-\mathbf{1 x}$, and (E)-1y), excellent yields were obtained. It can therefore be concluded that the substitution pattern is limited at $\mathrm{R}^{1}$ to either aryl or electron-poor moieties (such as the $\mathrm{CF}_{3}$ group). On the other hand, the $\mathrm{R}^{2}$ and $\mathrm{R}^{3}$ substituents can be varied to a larger extent; these may be electron-poor fluorinated groups, but importantly, also aryl groups with varied electron density, or even just hydrogen. It is important to highlight that TBD is able to isomerize not only fluorinated and electron poor alcohols, but also alcohols such as $1 \mathbf{s}-\mathbf{u}$, for which transition metal catalysts under basic conditions have been used. ${ }^{1,2}$

The base-catalyzed isomerization can also be applied to fluorinated allylic ethers $\mathbf{3 a}-\mathbf{d}$ (Scheme 2), ${ }^{8,9}$ giving access to synthetically valuable enol ethers. ${ }^{10}$ Even nonfluorinated terminal allylic ethers $3 \mathbf{e}, \mathbf{f}$ could be isomerized. Enol ethers $\mathbf{4 a}-\mathbf{d}$ were formed as single $(Z)$-isomers, and $\mathbf{4 e}$ and $\mathbf{4 f}$ were obtained as a 92:8 and 97:3 Z/E mixtures, respectively (see SI). Unfortunately, other allylic substrates such as allyl silyl ethers and allylic esters did not isomerized under the conditions described here (see SI, Scheme S1).

We then investigated whether the reaction is stereospecific (Table 2 and Table S2).,11 The isomerization of (R)-1a (99\% ee) took place in excellent yield and with an enantiospecificity (es; \% of the product formed by the stereospecific pathway as opposed to the competing unselective pathway) of $91 \%$ (entry 1 ). The es could be improved to $95 \%$ by decreasing the base loading to $2.5 \mathrm{~mol} \%$, although longer reaction times (18 h with $5 \mathrm{~mol} \%$ TBD and $72 \mathrm{~h}$ with $2.5 \mathrm{~mol} \%$ TBD) were needed (entries 2 and 3). Gratifyingly, at $80{ }^{\circ} \mathrm{C}$, the es was maintained and the reaction was completed in $18 \mathrm{~h}$ with $2.5 \mathrm{~mol} \% \mathrm{TBD}$ (entry 4). Other solvents were screened to assess the effect on the es (Table 2, entries 5-8). Interestingly, all solvents tested gave not only decreased es but also considerably lower yields (entries 5-8). This effect was more pronounced in solvents with higher polarity.

The stereospecific isomerization was then tested for a variety of substrates (Table 3). As expected, the same es (91\%) was obtained in the isomerization of (S)-1a (entry 2). Substrates $(R)-\mathbf{1 b}$ and $(R)-\mathbf{1 c}$ having electron-poor aryl groups at $\mathrm{R}^{1}$ gave the products with excellent es (96\% and 98\%, respectively, entries 4 and 5). For alcohols with electron-rich $R^{1},(R)$-1d and $(R)-1 e$ (entries 6 and 7), longer reaction times were needed to achieve good yields with es of $94 \%$ and $89 \%$, respectively. Naphthyl substituted ( $R$ )-1f gave similar results (entry 8). Lower yields were obtained in the isomerization of allylic alcohols $(R)-\mathbf{1} \mathbf{j}$ and $(R)-\mathbf{1 k}$, with electron-poor aromatics at $\mathrm{R}^{2}$ (entries 9-10). In addition, whereas a $p$-Cl substituent did not significantly affect the es (entry 9 ), a somewhat less efficient transfer of chirality was achieved when $\mathrm{R}^{2}=p-\mathrm{CF}_{3} \mathrm{C}_{6} \mathrm{H}_{4}$ (entry 10). On the other hand, exceptionally high es and good yields were obtained with alcohols $(R)-\mathbf{1 1}$ and $(R)-\mathbf{1 m}$, with electron-donating aromatics at $\mathrm{R}^{2}$ (entries $11-12$ ). Good transfer of chirality was also obtained with substrates bearing various fluorinated chains at $R^{3}[(R)-1 p$ and $(R)-1 q$, entries 13-14]. 
Scheme 2. Scope

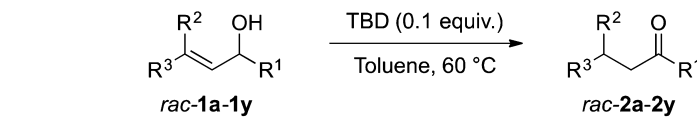<smiles>[X]c1ccc(C(O)C(CC)c2ccccc2)cc1</smiles>

(E)-1a-e

2a: $\mathrm{X}=\mathrm{H} ; 6 \mathrm{~h},>99(85) \%$

2b: $\mathrm{X}=\mathrm{Br} ; 3 \mathrm{~h},>99(90) \%$

2c: $\mathrm{X}=\mathrm{CF}_{3} ; 1 \mathrm{~h},>99(84) \%$

2d: $X=M e ; 36 h,>99(95) \%$

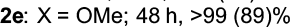

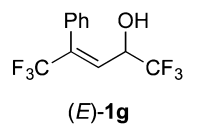

2g: $18 \mathrm{~h},>99(50) \%[\mathrm{~b}, \mathrm{c}, \mathrm{d}]$<smiles>[X]c1ccc(/C(=C/C(O)c2ccccc2)C(F)(F)F)cc1</smiles>

$(E)-\mathbf{1 j}-\mathbf{m}$

2j: $\quad \mathrm{X}=\mathrm{Cl} ; 18 \mathrm{~h},>99(86) \%$ 2k: $\mathrm{X}=\mathrm{CF}_{3} ; 18 \mathrm{~h},>99(88) \%$

2I: $X=M e ; 18 h,>92(80) \%$

2m: $X=O M e ; 18$ h, >99 (89)\%<smiles>OC(/C=C(\[Tl])c1ccccc1)c1ccccc1</smiles>

(E)-1p-q

2p: $\mathrm{R}^{3}=\mathrm{CF}_{2} \mathrm{CF}_{3} ; 48 \mathrm{~h}, 77^{[\mathrm{el}]}(62) \%^{[\mathrm{[a]}}$ 2q: $\mathrm{R}^{3}=\mathrm{CF}_{2} \mathrm{CF}_{2} \mathrm{CF}_{3} ; 48 \mathrm{~h}, 82^{[\mathrm{e}]}(71) \%$ [a]

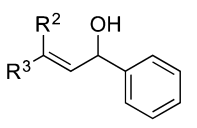

$(E)-1 \mathbf{v},(Z)-1 \mathbf{v}$

v: From $(E)-1 v$

$\mathrm{R}^{2}=\mathrm{CH}_{3} \mathrm{R}^{3}=\mathrm{Ph} ; 18 \mathrm{~h}, 62(50) \%$

2v: From (Z)-1v:

$\mathrm{R}^{2}=\mathrm{Ph}, \mathrm{R}^{3}=\mathrm{CH}_{3} ; 18 \mathrm{~h}, 20(12) \%$<smiles>OC(/C=C(\c1ccccc1)C(F)(F)F)c1ccccc1</smiles>

(Z)-1a

2a: $18 \mathrm{~h}, 85(62) \%\left[{ }^{[a]}\right.$<smiles>O=[N+]([O-])/C=C(\c1ccccc1)C(F)(F)F</smiles>

$(E)-1 \mathrm{~h}$<smiles>OC(C=C(C(F)(F)F)C(F)(F)F)c1ccc2ccccc2c1</smiles>

$(E)-1 \mathbf{f}$ 2f. $18 \mathrm{~h},>99(85) \%$<smiles>OC(C=C(C(F)(F)F)C(F)(F)F)c1ccccc1</smiles>

2i: $18 \mathrm{~h}, 30 \%\left[{ }^{[b]}\right.$<smiles>[O-][N+]=CC(O)c1ccccc1</smiles>

$(E)-1 \mathbf{n}$<smiles>OC(C=C(F)F)c1ccccc1</smiles>

$(E)-10$

20: $18 \mathrm{~h},>99(65) \%[\mathrm{~d}]$

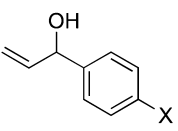

1s-u

2s: $\mathrm{X}=\mathrm{H} ; 18 \mathrm{~h},>99(90) \%{ }^{[\mathrm{b}]}$

2t: $\mathrm{X}=\mathrm{Br} ; 18 \mathrm{~h},>99(74) \%\left[{ }^{[b]}\right.$ 2u: $\mathrm{X}=i-\mathrm{Bu} ; 18 \mathrm{~h}, 46(40) \%^{[\mathrm{b}]}$

2r: $18 \mathrm{~h},>99(80) \%{ }^{[b, c]}$

$\mathrm{R}^{2} \mathrm{OH}$<smiles>[R]C([R])=CC(C)c1ccccc1</smiles>

1w, $(Z)-1 \mathbf{x},(E)-1 \mathbf{x}$

$(E)-1 y$

2w: $\mathrm{R}^{2}=\mathrm{R}^{3}=\mathrm{Ph} ; 18 \mathrm{~h},>99(65) \%[\mathrm{~b}, \mathrm{c}]$

2x: From (Z)-1x: $\mathrm{R}^{2}=p-\mathrm{BrC}_{6} \mathrm{H}_{4}, \mathrm{R}^{3}=\mathrm{Ph} ; 18 \mathrm{~h},>99(73) \%\left[\%^{[\mathrm{b}]}\right.$

2x: From (E)-1x: $\mathrm{R}^{2}=\mathrm{Ph}, \mathrm{R}^{3}=p-\mathrm{BrC}_{6} \mathrm{H}_{4} ; 18 \mathrm{~h},>99(75) \%[$ [b]

2y: $R^{2}=P h, R^{3}=C_{6} F_{5} ; 18 h,>99(68) \%[b]$

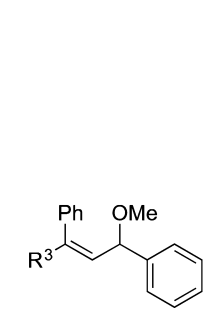

(E)-3a-b<smiles>[R]C([R])=CC([R])Pc1ccccc1</smiles>

rac-3a-3f

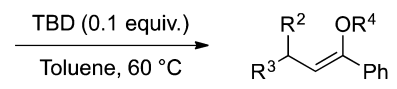

rac-4a-4f

(Z)-4a: $\mathrm{R}^{3}=\mathrm{CF}_{3} ; 18 \mathrm{~h},>99(86) \%$

(Z)-4b: $\mathrm{R}^{3}=\mathrm{CF}_{2} \mathrm{CF}_{2} \mathrm{CF}_{3} ; 72 \mathrm{~h}, 88(69) \%$<smiles>FC(F)(F)C(=CC(c1ccccc1)c1ccccc1)C(F)(F)C(F)(F)F</smiles>

$(E)-3 c$

Z)-4c: 18 h, >99 (80)\%<smiles>FC(F)(F)C(=CC(OCc1ccccc1)c1ccccc1)C(F)(F)F</smiles>

$(E)-\mathbf{3 d}$

(Z)-4d: 36 h, 94 (76)\%<smiles>[R]C=CC(OC)c1ccccc1</smiles>

(E)-3e, $\mathbf{3 f}$

(Z/E)-4e: $\mathrm{R}^{3}=\mathrm{Ph}(\mathrm{Z} / \mathrm{E}=92: 8) ; 18 \mathrm{~h}$, $75(53) \%[b, c]$

(Z/E)-4f: $\mathrm{R}^{3}=\mathrm{H} \quad(\mathrm{Z} / \mathrm{E}=97: 3) ; 18 \mathrm{~h}$, $60(45) \%[b, c]$

${ }^{a} 80{ }^{\circ} \mathrm{C} .{ }^{b} \mathrm{TBD}$ (0.2 equiv), reflux. ${ }^{c}$ By NMR spectroscopy with an internal standard. ${ }^{d}$ Volatile. ${ }^{e}$ Conversion. ${ }^{f}$ Yield by ${ }^{19} \mathrm{~F}$ NMR spectroscopy (isolated in parentheses).

Importantly, the ee of the products could be increased up to $99 \%$ by simple recrystallization. It must be mentioned that the isomerizations are also stereospecific when bases such as $\mathrm{Cs}_{2} \mathrm{CO}_{3}, \mathrm{NaH}, t-\mathrm{BuOK}$, and DBU were used (See SI, Table S1).
The isomerization of chiral allylic ethers $(R)-\mathbf{3} \mathbf{a}-\mathbf{c}$ also proceeded remarkably well with $5 \mathrm{~mol} \% \mathrm{TBD}$ at $80{ }^{\circ} \mathrm{C}(97-99 \%$ es, entries 15-17). To the best of our knowledge, this is the first stereospecific isomerization of allylic ethers to be reported. 
Table 2. Base-Catalysed Stereospecific Isomerization of 1a

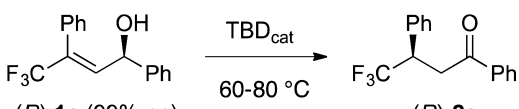

$(R)-1 \mathrm{a}(99 \%$ ee $) \quad{ }^{60-80^{\circ} \mathrm{C}} \quad(R)-2 \mathrm{a}$

\begin{tabular}{|c|c|c|c|c|c|c|}
\hline entry & $\begin{array}{c}\text { TBD } \\
(\mathrm{mol} \%)\end{array}$ & solvent & $\begin{array}{c}t(\mathrm{~h}) / T \\
\left({ }^{\circ} \mathrm{C}\right)\end{array}$ & $\begin{array}{l}2 a^{a} \\
(\%)\end{array}$ & $\begin{array}{c}\text { ee } \\
(\%)\end{array}$ & $\begin{array}{c}\text { es } \\
(\%)\end{array}$ \\
\hline 1 & 10 & toluene & $6 / 60$ & 85 & 90 & 91 \\
\hline 2 & 5 & toluene & $18 / 60$ & 84 & 93 & 94 \\
\hline 3 & 2.5 & toluene & $72 / 60$ & 84 & 94 & 95 \\
\hline 4 & 2.5 & toluene & $18 / 80$ & 82 & 94 & 95 \\
\hline 5 & 2.5 & 1,4-dioxane & $18 / 80$ & 71 & 84 & 85 \\
\hline 6 & 2.5 & THF & $18 / 80$ & 30 & 74 & 75 \\
\hline 7 & 2.5 & $\mathrm{CH}_{2} \mathrm{Cl}_{2}$ & $18 / 80$ & 28 & 80 & 81 \\
\hline 8 & 2.5 & $\mathrm{CH}_{3} \mathrm{CN}$ & $18 / 80$ & 27 & 60 & 61 \\
\hline
\end{tabular}

${ }^{a}$ Isolated yields.

Table 3. Stereospecific Isomerizations

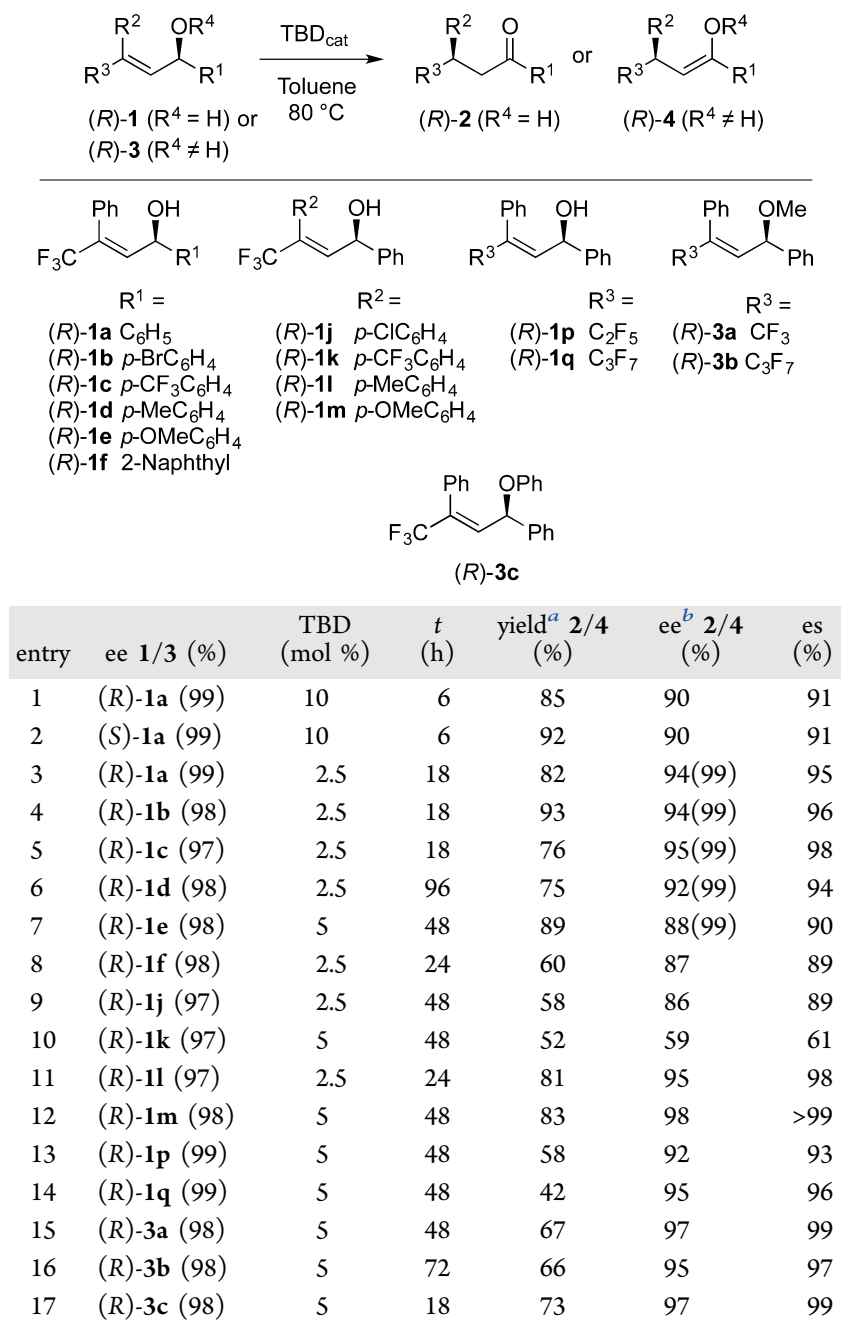

${ }^{a}$ Isolated yields. ${ }^{b}$ In parentheses, ee after recrystallization.

The electronic influence of $\mathrm{R}^{1}$ was investigated further. A Hammett plot under noncompetition conditions is shown in Figure 1. A positive $\rho$ value of 1.87 was obtained, indicating that a partial negative charge $\left(\delta^{-}\right)$is formed in the rate-determining transition state. ${ }^{12}$ These results, together with a large kinetic isotope effect (KIE) of $\geq 5.0$, support a mechanism through a ratelimiting deprotonation of $\mathrm{C}_{1}$.
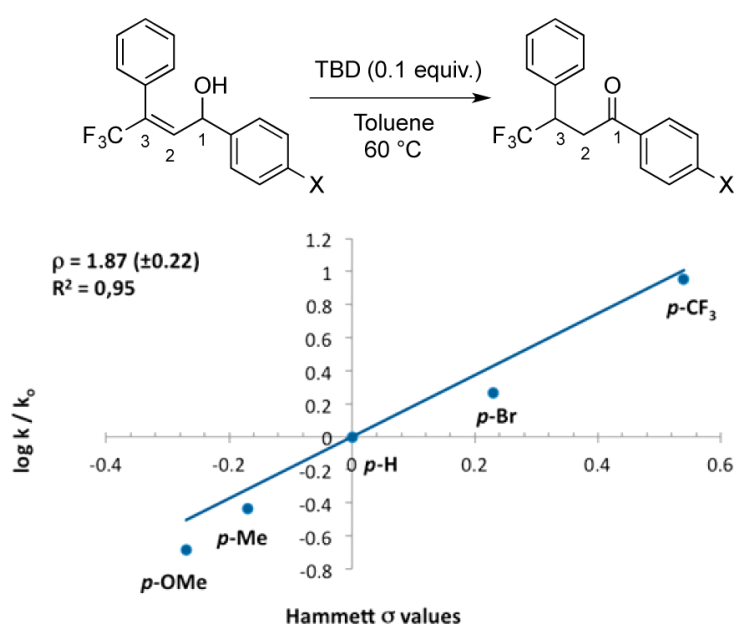

Figure 1. Hammett plot.

The isomerization of $\mathbf{1 a}-d_{1}(96 \% \mathrm{D})$ afforded $2 \mathrm{a}-d$ with only $68 \% \mathrm{D}_{\text {TОT }}\left(20 \%\right.$ at $\mathrm{C}_{2}$ and $48 \% \mathrm{C}_{3}$ distributed in a mixture of $\mathbf{2 a}-d_{0}(32 \%), \mathbf{2 a}-d_{1}(47 \%), \mathbf{2 a}-d_{2}(17.6 \%)$, and $\mathbf{2 a}-d_{3}(3.4 \%)$, Scheme $3 \mathrm{a}$ and SI). In an attempt to understand the net low amount of $\mathrm{D}$ at $\mathrm{C}_{3}$, $\mathbf{1 a}$ was treated with partially deuterated TBD $\left(N-d_{1}-\right.$ TBD, Scheme $\left.3 b\right)$. Notably, $6 \%$ of $\mathrm{D}$ was found at $\mathrm{C}_{3}$ in $2 \mathrm{a}$, indicating that the $\mathrm{H}$ at $\mathrm{C}_{3}$ in Scheme $3 \mathrm{a}$ originates to some extent from the base. Importantly, in the isomerization of 1a- $d_{1}$, the $\mathrm{D}$ content at $\mathrm{C}_{1}$ (i.e., 96\%) remains constant in the starting alcohol as the reaction proceeds; thus the deprotonation step is irreversible. The isomerization of ether $3 \mathrm{a}-d_{1}(96 \% \mathrm{D}$, Scheme $3 c$ ) gave $4 a-d_{1}$ with $78 \% \mathrm{D}$, which is only slightly lower than the expected $86 \% \mathrm{D}$. This might be due to traces of water in the reaction medium. From a crossover experiment between $1 \mathrm{a}-d_{1}$ and $1 \mathrm{n}$, with similar reaction rates (Scheme 3d), it can be concluded that the main reaction pathway involves an intramolecular 1,3-H/D shift, since only $4 \%$ of $\mathrm{D}$ was detected at $\mathrm{C}_{3}$ in $\mathbf{2 n}$.

To further test the proposed mechanism via deprotonation of the $\mathrm{C}_{1}-\mathrm{H}$ bond, we studied the isomerization with DFT (B3LYP-D3/aug-cc-pVTZ) (Figure 2). In agreement with the experimental studies, the deprotonation was found to be the rds, with an activation free energy of $19.6 \mathrm{kcal} / \mathrm{mol}\left(\mathrm{TS}_{\mathrm{I}}\right)$, relative to the hydrogen bonded prereactive complex. After this first step, an intimate ion pair ${ }^{14}$ composed of the allylic anion and the protonated base is formed. The computational results suggest that the anion can be protonated either intramolecularly $\left(\mathrm{TS}_{\mathrm{II}}\right)$ by the hydroxyl group or intermolecularly by the conjugate acid of TBD $\left(\mathrm{TS}_{\mathrm{IIb}}\right)$. Both pathways have similarly low activation energies $(\sim 4 \mathrm{kcal} / \mathrm{mol})$. This explains the low deuterium content at $C_{3}$ in the ketone product obtained upon isomerizing $\mathbf{1 a}-d_{1}$ (Scheme $3 \mathrm{a}$ ).

The theoretical studies also shed light onto the enantiospecificity of the reaction. The formation of the intimate ion pair prevents racemization of the allylic anion, which would result in inefficient transfer of chirality. Indeed, increasing the polarity of the solvent resulted in lower es values, due to insufficient ion pairing (vide supra, Table 2 and Table S2). Furthermore, the presence of a strong electron-withdrawing group on the phenyl ring at $\mathrm{R}^{2}$ (i.e., $\mathbf{2 k}$ ) results in poorer transfer of chirality. This may be due to formation of a more stable allylic anion in this instance, which enables rotation with subsequent partial loss of stereochemical information. A similar mechanistic rationale has been proposed for a proton migration with chirality transfer mediated by DBU. ${ }^{15}$ 


\section{Scheme 3. Deuterium Labeling Studies}

a)<smiles>[2H]C(O)(/C=C(/c1ccccc1)C(F)(F)F)c1ccccc1</smiles>

$1 \mathrm{a}-d_{1}(96 \% \mathrm{D})$ b)<smiles>OC(/C=C(/c1ccccc1)C(F)(F)F)c1ccccc1</smiles>

$1 \mathrm{a}$
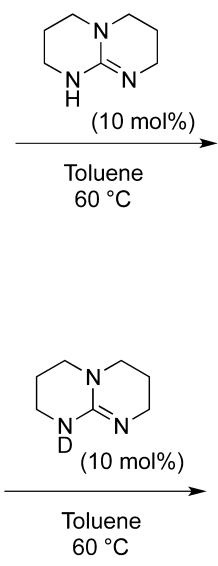

$60^{\circ} \mathrm{C}$

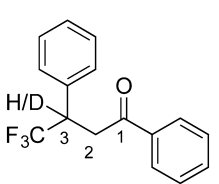

2a $\left(48 \% \mathrm{D}\right.$ at $\left.\mathrm{C}_{3}\right)$ c)<smiles>COC(/C=C(/c1ccccc1)C(F)(F)F)(c1ccccc1)c1ccccc1</smiles>

$3 a-d_{1}(96 \%$ D)<smiles>[2H]C(O)(/C=C(/c1ccccc1)C(F)(F)F)c1ccccc1</smiles>

d)<smiles>C/C(=C\[C@@H](O)c1ccccc1)C(F)(F)F</smiles>

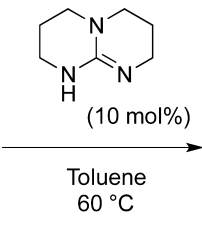

$60^{\circ} \mathrm{C}$<smiles>C1CN=C2NCCCN2C1</smiles>

(10 mol\%)

Toluene $60^{\circ} \mathrm{C}$

2a $\left(6 \%\right.$ D at $\left.C_{3}\right)$<smiles>CO/C(=C\C(O)(c1ccccc1)C(F)(F)F)c1ccccc1</smiles>

4a $\left(78 \% \mathrm{D}\right.$ at $\left.\mathrm{C}_{3}\right)$<smiles>O=C(CC(O)(c1ccccc1)C(F)(F)F)c1ccccc1</smiles>

2a $\left(48 \% \mathrm{D}\right.$ at $\left.\mathrm{C}_{3}\right)$<smiles>CC(O)(CC(=O)c1ccccc1)C(F)(F)F</smiles>

2n (4\% D at $\left.\mathrm{C}_{3}\right)$

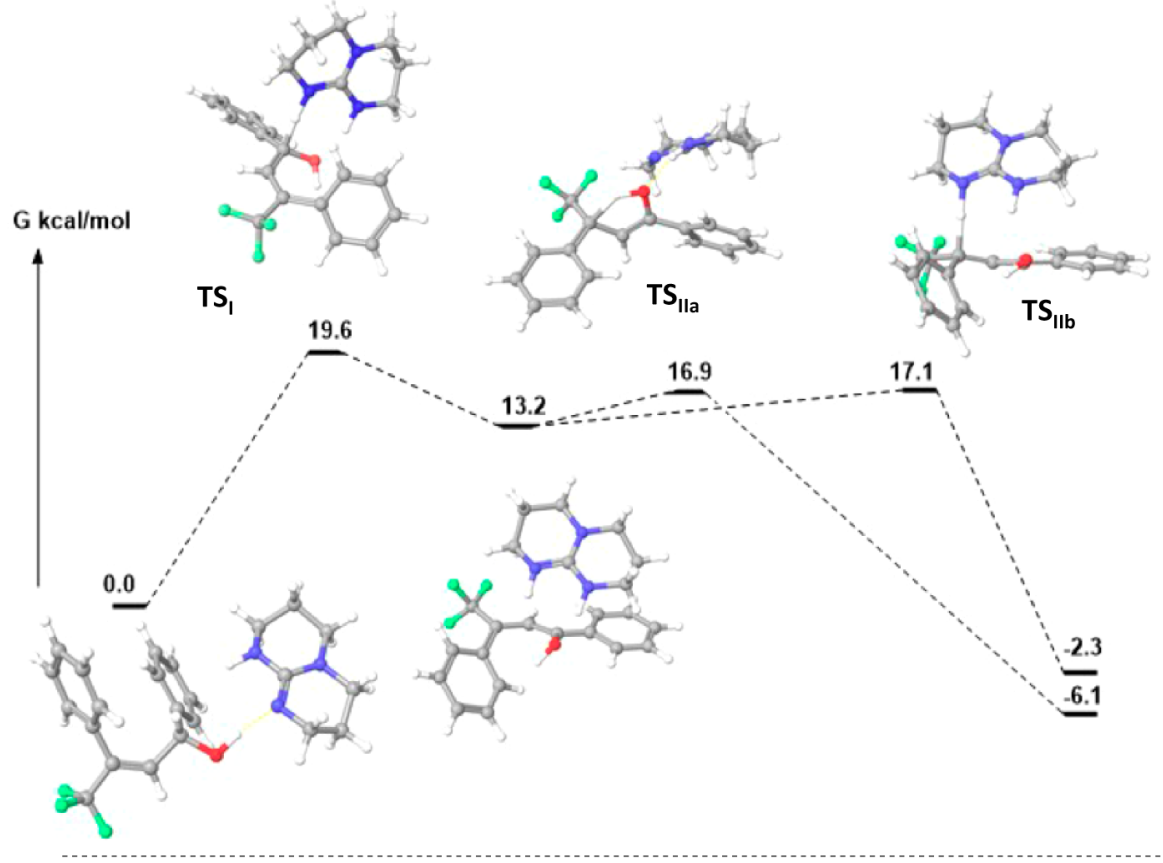

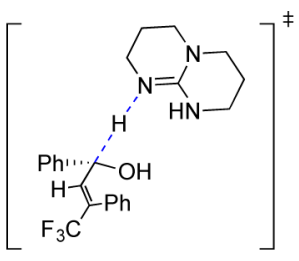

$\mathrm{TS}_{1}$

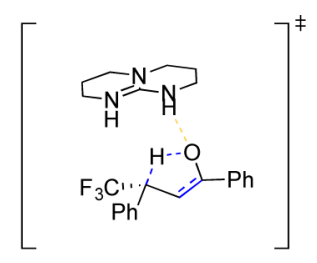

$\mathrm{TS}_{\text {IIa }}$

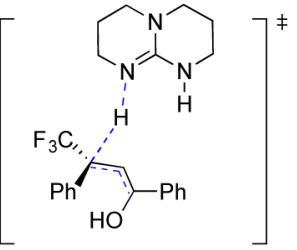

$\mathrm{TS}_{\| \mathrm{lb}}$

Figure 2. Free energy profile: isomerization of 1 a by TBD.

The isomerization mechanism proposed here differs from that proposed for the $\mathrm{Ru}$-catalyzed isomerization of trifluoromethylated allylic alcohols in the presence of base. ${ }^{4}$ In the latter, after a $\beta$-hydride elimination step yielding a ruthenium hydride species and an enone intermediate, it was proposed that a migratory insertion from a single face accounted for the efficient chirality transfer. Overall, this resulted in a formal $\mathrm{Ru}$-catalyzed intramolecular suprafacial hydride shift. We have demonstrated here that for these particular electron-poor alcohols, the stereospecific isomerization can be simply mediated by a base through a deprotonation/protonation sequence that occurs at mild reaction conditions. Importantly, the base-mediated reaction can account for the same levels of enantiospecificity. The best results during our investigations were obtained with TBD, which could be used in loadings as low as $2.5 \mathrm{~mol} \%$. Other bases such as $\mathrm{Cs}_{2} \mathrm{CO}_{3}, \mathrm{NaH}$, or DBU also mediated the 
stereospecific isomerization of allylic alcohols, although in stoichiometric amounts. It is important to mention that higher yields are obtained with the $\mathrm{Ru} / \mathrm{Cs}_{2} \mathrm{CO}_{3}{ }^{4}$ system than when $\mathrm{Cs}_{2} \mathrm{CO}_{3}$ is used as the sole reagent; thus the $\mathrm{Ru}$ catalyst must play a specific role together with the base in the former case. Nevertheless, the noninnocent role of basic additives in the isomerization of electron-poor or aromatic allylic alcohols must be taken into consideration.

\section{CONCLUSION}

We have developed the first metal-free base-catalyzed stereospecific isomerization of allylic alcohols. The method enables the transformation of a large variety of aromatic and electrondeficient allylic alcohols into carbonyl compounds under mild reaction conditions. We have also presented the first stereospecific isomerization of allylic ethers. This base-catalyzed metal-free method affords chiral enol ethers, which are also very valuable synthetic intermediates in organic synthesis. Experimental and computational investigations indicate that the transfer of the chirality only occurs upon formation of an intimate ion pair after the rate limiting deprotonation step. This study represents a unique example in which organic ion-pairing enables transfer of chirality in readily available chiral organic allylic substrates using a simple nonchiral base.

\section{EXPERIMENTAL SECTION}

4.1. General Method for the Isomerization of Allylic Alcohols and Ethers by Base. A pressure tube was charged with the corresponding allylic substrate $(0.18 \mathrm{mmol}, 1$ equiv $)$, 1,5,7-triazabicyclo[4.4.0] dec-5-ene ( $0.018 \mathrm{mmol}, 2.5 \mathrm{mg}, 0.1$ equiv), and $1.8 \mathrm{~mL}$ of toluene. The mixture was allowed to react at $60{ }^{\circ} \mathrm{C}$ overnight, and the reaction was quenched with $\mathrm{H}_{2} \mathrm{O}(5 \mathrm{~mL})$ and extracted with $\mathrm{Et}_{2} \mathrm{O}(3 \times 5 \mathrm{~mL})$. The solvent was removed under reduced pressure to yield the product. Further information about experimental details and characterization of new compounds can be found in the Supporting Information.

\section{ASSOCIATED CONTENT}

\section{S Supporting Information}

The Supporting Information is available free of charge on the ACS Publications website at DOI: 10.1021/jacs.6b08350.

Experimental details, copies of ${ }^{1} \mathrm{H},{ }^{13} \mathrm{C}$, and ${ }^{19} \mathrm{~F}$ NMR spectra, and chromatograms of racemic and chiral products (PDF)

\section{AUTHOR INFORMATION}

\section{Corresponding Author}

*belen.martin.matute@su.se

\section{Author Contributions}

${ }^{\S}$ S.M.-E. and A.S.-M. contributed equally.

\section{Notes}

The authors declare no competing financial interest.

\section{ACKNOWLEDGMENTS}

This project was supported by the Swedish Research Council (VR), and the Knut and Alice Wallenberg Foundation. B.M.-M. was supported by VINNOVA through a VINNMER grant, and A.V.-R. was supported by the Wenner-Gren Foundation through a postdoctoral grant.

\section{REFERENCES}

(1) For reviews and accounts on transition metal-catalyzed allylic alcohol isomerizations, see: (a) Uma, R.; Crevisy, C.; Gree, R. Chem. Rev. 2003, 103, 27-52. (b) Cadierno, V.; Crochet, P.; Gimeno, J. Synlett 2008, 2008, 1105-1124. (c) Ahlsten, N.; Bartoszewicz, A.; Martín-Matute, B. Dalton Trans. 2012, 41, 1660-1670. (d) LorenzoLuis, P.; Romerosa, A.; Serrano-Ruiz, M. ACS Catal. 2012, 2, 10791086. (e) Cahard, D.; Gaillard, S.; Renaud, J. L. Tetrahedron Lett. 2015, 56, 6159-6169. (f) Li, H.; Mazet, C. Acc. Chem. Res. 2016, 49, 12321241.

(2) Selected transition metal-catalyzed examples: (a) Ito, M.; Kitahara, S.; Ikariya, T. J. Am. Chem. Soc. 2005, 127, 6172-6173. (b) Martín-Matute, B.; Bogár, K.; Edin, M.; Kaynak, F. B.; Bäckvall, J.E. Chem. - Eur. J. 2005, 11, 5832-5842. (c) Cadierno, V.; GarcíaGarrido, S. E.; Gimeno, J.; Varela-Álvarez, A.; Sordo, J. A. J. Am. Chem. Soc. 2006, 128, 1360-1370. (d) Voronova, K.; Purgel, M.; Udvardy, A.; Bényei, A. C.; Kathó, A.; Joó, F. Organometallics 2013, 32, 43914401. (e) Lastra-Barreira, B.; Díez, J.; Crochet, P. Green Chem. 2009, 11, 1681-1686. For asymmetric isomerizations of primary allylic alcohols, see: (f) Tanaka, K.; Qiao, S.; Tobisu, M.; Lo, M. M.-C.; Fu, G. C. J. Am. Chem. Soc. 2000, 122, 9870-9871. (g) Mantilli, L.; Gérard, D.; Torche, S.; Besnard, C.; Mazet, C. Angew. Chem., Int. Ed. 2009, 48, 5143-5147. (h) Wu, R.; Beauchamps, M. G.; Laquidara, J. M.; Sowa, J. R., Jr Angew. Chem., Int. Ed. 2012, 51, 2106-2110. (i) Arai, N.; Sato, K.; Azuma, K.; Ohkuma, T. Angew. Chem., Int. Ed. 2013, 52, 7500-7504. For asymmetric isomerizations of secondary cyclic allylic alcohols, see: (j) Kress, S.; Johnson, T.; Weisshar, F.; Lautens, M. ACS Catal. 2016, 6, 747-750. And ref 2a.

(3) (a) Trost, B. M.; Kulawiec, R. J. J. Am. Chem. Soc. 1993, 115, 2027-2036. (b) Trost, B. M.; Indolese, A. F.; Müller, T. J. J.; Treptow, B. J. Am. Chem. Soc. 1995, 117, 615-623.

(4) (a) Bizet, V.; Pannecoucke, X.; Renaud, J.-L.; Cahard, D. Angew. Chem., Int. Ed. 2012, 51, 6467-6470. (b) Bizet, V.; Pannecoucke, X.; Renaud, J.-L.; Cahard, D. J. Fluorine Chem. 2013, 152, 56-61.

(5) (a) Dimmel, D. R.; Fu, W. Y.; Gharpure, S. B. J. Org. Chem. 1976, 41, 3092-3096. (b) Schmid, G. A.; Borschberg, H.-J. Helv. Chim. Acta 2001, 84, 401-415. (c) Johnston, A. J. S.; McLaughlin, M. G.; Reid, J. P.; Cook, M. J. Org. Biomol. Chem. 2013, 11, 7662-7666. (d) Zheng, H.-X.; Xiao, Z.-F.; Yao, C.-Z.; Li, Q.-Q.; Ning, X.-S.; Kang, Y.-B.; Tang, Y. Org. Lett. 2015, 17, 6102-6105. (e) Mondal, K.; Mondal, B.; Pan, S. C. J. Org. Chem. 2016, 81, 4835-4848.

(6) (a) Ahlsten, N.; Martín-Matute, B. Chem. Commun. 2011, 47, 8331-8333. (b) Ahlsten, N.; Bermejo Gómez, A.; Martín-Matute, B. Angew. Chem., Int. Ed. 2013, 52, 6273-6276. (c) Gómez, A. B.; Erbing, E.; Batuecas, M.; Vázquez-Romero, A.; Martín-Matute, B. Chem. - Eur. J. 2014, 20, 10703-10709 and references therein.

(7) Superbases in catalytic reactions: Nacsa, E. D.; Lambert, T. H. J. Am. Chem. Soc. 2015, 137, 10246-10253.

(8) Selected recent examples of transition-metal-catalyzed isomerization of allylic ethers: (a) Courchay, F. C.; Sworen, J. C.; Ghiviriga, I.; Abboud, K. A.; Wagener, K. B. Organometallics 2006, 25, 60746086. (b) Varela-Álvarez, A.; Sordo, J. A.; Piedra, E.; Nebra, N.; Cadierno, V.; Gimeno, J. Chem. - Eur. J. 2011, 17, 10583-10599. (c) Urbala, M. Appl. Catal., A 2015, 505, 382-393.

(9) Scarce examples of base-mediated isomerization of allylic ethers: (a) Su, C.; Williard, P. G. Org. Lett. 2010, 12, 5378-5381. (b) Reid, J. P.; McAdam, C. A.; Johnston, A. J. S.; Grayson, M. N.; Goodman, J. M.; Cook, M. J. J. Org. Chem. 2015, 80, 1472-1498.

(10) Enol ethers as synthetic intermediates: (a) Mahrwald, R., Ed. Modern Methods in Stereoselective Aldol Reactions, 1st ed.; Wiley-VCH: Weinheim, Germany, 2013. (b) Kusama, H.; Ebisawa, M.; Funami, H.; Iwasawa, N. J. Am. Chem. Soc. 2009, 131, 16352-16353. (c) Vitale, A.; Bongiovanni, R.; Ameduri, B. Chem. Rev. 2015, 115, 8835-8866.

(11) Synthesis of chiral allylic alcohols and synthetic applications: Lumbroso, A.; Cooke, M. L.; Breit, B. Angew. Chem., Int. Ed. 2013, 52, 1890-1932.

(12) (a) Hammett, L. P. J. Am. Chem. Soc. 1937, 59, 96-103. (b) Lupp, D.; Christensen, N. J.; Fristrup, P. Understanding Organometallic Reaction Mechanisms and Catalysis: Computational and 
Experimental Tools, 1st ed.; Ananikov, V. P., Ed.; Wiley-VCH: Weinheim, Germany, 2015; pp 187-215.

(13) Simmons, E. M.; Hartwig, J. F. Angew. Chem., Int. Ed. 2012, 51, 3066-3072.

(14) Ion-pairing in catalytic processes: (a) Rueping, M.; Uria, U.; Lin, M.-Y.; Atodiresei, I. J. Am. Chem. Soc. 2011, 133, 3732-3735. (b) Brak, K.; Jacobsen, E. N. Angew. Chem., Int. Ed. 2013, 52, 534561. (c) Mahlau, M.; List, B. Angew. Chem., Int. Ed. 2013, 52, 518533. (d) Xue, H.; Jiang, D.; Jiang, H.; Kee, C. W.; Hirao, H.; Nishimura, T.; Wong, M. W.; Tan, C.-H. J. Org. Chem. 2015, 80, $5745-5752$.

(15) For a related DBU-catalyzed stereospecific isomerization through proton transfer, see: Dabrowski, J. A.; Haeffner, F.; Hoveyda, A. H. Angew. Chem., Int. Ed. 2013, 52, 7694-7699. 